\title{
La orientación emprendedora femenina en la industria textil y de la confección, en Moroleón, Guanajuato, México
}

\section{Women's entrepreneurial orientation in the textile and clothing industry, in Moroleón, Guanajuato, Mexico}

CÁRCAMO-SOLIS, María de Lourdest**', DÍAZ-ZAMUDIO, Mayra Joceline' y ARROYO-LÓPEZ, María del Pilar"

'Universidad de Guanajuato, Departamento de Estudios Multidisciplinarios, División de Ingenierías, Campus IrapuatoSalamanca, Sede Yuriria, México.

"Tecnológico de Monterrey, EGADE Business School, Eduardo Monroy No. 2000, San Antonio Buenavista. Toluca. 50110, México.

ID $1^{\mathrm{er}}$ Autor: María de Lourdes, Cárcamo-Solís / ORC ID: 0000-0003-4671-1644, CVU/SNI CONACYT ID: 241049

ID $1^{\text {er }}$ Coautor: Mayra Joceline, Díaz-Zamudio / ORC ID: 0000-0001-8176-7673

ID $2^{\text {do }}$ Coautor: María del Pilar, Arroyo-López / ORC ID: 0000-0002-6160-871X, CVU/SNI CONACYT ID: 202927

DOI: $10.35429 / J E D .2020 .23 .7 .14 .31$

Recibido: Abril 10, 2020; Aceptado: Junio 30, 2020

\begin{abstract}
Resumen
El objetivo de investigación fue analizar cómo el papel de la mujer en la gerencia en las PYMES del sector textil y de la confección (STC), en la región sur del estado de Guanajuato, se manifiesta en las cinco dimensiones de la Orientación Emprendedora (OE). Metodológicamente este trabajo es cuantitativo y explicativo, basado en un modelo de ecuaciones estructurales estimado a partir de la información de la aplicación de un cuestionario validado a 103 mujeres gerentes de la región mencionada, contribuyendo a incrementar teórica y empíricamente los estudios sobre la $\mathrm{OE}$ y promoverla para un mayor impulso de los negocios con dirigentes femeninas que abonen al desarrollo socioeconómico de la región. Como conclusión, las mujeres gerentes del STC desarrollan las cinco dimensiones de la OE: la innovación, al generar nuevos modelos de prendas y estar a la vanguardia. La toma de riegos, al invertir en materia prima o maquinaria. La proactividad, siempre buscan nuevas maneras de hacer las actividades que desempeñan en beneficio del negocio que lideran, y conservan la autonomía al tomar decisiones que mejoren el desempeño de su negocio. La competitividad agresiva, al implementar nuevas formas de atender a los clientes para sobresalir en comparación con sus competidores.
\end{abstract}

Orientación emprendedora, Mujer gerente, Sector textil y de la confección

\begin{abstract}
The research objective is to analyze how the role of women in management in SMEs in the textile and clothing sector (TCS), in the southern region of the state of Guanajuato, manifests itself in the five dimensions of Entrepreneurial Orientation (EO). Methodologically this work is quantitative and explanatory, based on a model of structural equations estimated by using the information of a validated questionnaires applied to 103 women managers of the above-mentioned region, contributing to theoretically and empirically increament of the literature on the $\mathrm{OE}$ and promote it for a greater boost of business with female leaders who may contribute the socioeconomic development of the region. In conclusion, the women managers of the STC develop the five dimensions of the OE: innovation, by generating new models of garments and being at the forefront. Watering, by investing in raw materials or machinery. Proactivity because they are always looking for new ways to do the activities, they perform for the benefit of the business they lead and retain autonomy by making decisions that improve the performance of their business. Aggressive competitiveness by implementing new ways to conquer customers to excel compared to their competitors.
\end{abstract}

Entrepreneurial orientation, Female manager, Textile and clothing sector

Citación: CÁRCAMO-SOLIS, María de Lourdes, DÍAZ-ZAMUDIO, Mayra Joceline y ARROYO-LÓPEZ, María del Pilar. La orientación emprendedora femenina en la industria textil y de la confección, en Moroleón, Guanajuato, México. Revista de Desarrollo Económico. 2020. 7-23:14-31.

\footnotetext{
* Correspondencia al Autor: (Correo electrónico: mlcarcamo@ugto.mx)

$\uparrow$ Investigador contribuido como primer autor.
} 


\section{Introducción}

La participación de la mujer en la gerencia y con una postura de Orientación Emprendedora (OE) en las pequeñas y medianas empresas (PYMES) ha sido un tema poco explorado y se le ha conferido poca importancia (Afandi \& Kermani, 2014; Fuentes, Bojica \& Arroyo, 2010). Si se analiza la literatura se podrán encontrar escasos estudios que aborden a la OE desde un enfoque de género. Dicha relación entre OE y la mujer gerente es importante, debido a que permite reconocer y definir cómo las mujeres gerentes manifiestan la caracterización de OE y crean riqueza al desarrollar las PYMES del sector textil y de la confección (STC) en el Sur del estado de Guanajuato.

En los estudios planteados sobre el papel de las mujeres en la OE, no se ha podido llegar a una conclusión sobre las aportaciones que tienen o el impacto que generan. Autores como Tsyganova y Shirokova (2010) opinan que las mujeres no tienen un impacto tan significativo en la OE, mientras que Kundu y Rani (2004) detectaron que las aspirantes a gerentes logran puntaciones altas en la OE.

Por otro lado, autores como Júnior y Giménez (2012) pudieron percibir porcentajes significativos en los puntajes de implementación del espíritu empresarial (Fellnhofer, Puumalainen, \& Sjögrén, 2016). En la actualidad, no se ha podido describir con certeza la participación de la mujer gerente en las empresas y cómo ejecutan una postura emprendedora en STC. Por eso, el interés de esta investigación es detectar cómo se desarrolla la OE femenina en el STC, con la finalidad de promover una mayor participación de la mujer gerente en este sector, ya que queremos probar que su $\mathrm{OE}$ en puestos gerenciales tiene un efecto multiplicador sobre la productividad, la eficiencia y el desarrollo económico sostenido de la región Sur del estado de Guanajuato.

Asimismo, Kickul, Liao, Gundry, \& Iakovleva (2010) concluyeron que las mujeres gerentes pueden identificar oportunidades, descubrir y explotar los recursos, y cuentan con habilidades esenciales para ser emprendedoras (Fellnhofer, 2016).
Richard, Barnett, Dwyer, \& Chadwick (2004) opinan que la OE arrojarán mejores resultados si se implementan equipos de trabajo mixtos en las empresas y se deja de lado la diferencia de géneros. Pues a pesar, de las diferencias que puedan existir entre géneros, éstas pueden complementarse de una manera más satisfactoria y benéfica para las PYMES (Zimmerman \& Brouthers, 2012).

Es por ello, que las empresas deben considerar el rol que juega la mujer en puestos de la alta gerencia, debido principalmente a que éstas tienen una mayor tendencia al emprendimiento y así, generar un mayor rendimiento en dichas organizaciones, ayudando a obtener un mejor resultado en las dimensiones de la $\mathrm{OE}$ ya que saben aprovechar todos los recursos que tienen disponibles (Velazquez, 2014). También, se considera que las mujeres líderes en estos cargos gerenciales están orientadas hacia las relaciones interpersonales (Francoise, Julián \& Mejía, 2012). Con el pasar del tiempo y de acuerdo con la literatura, se ha considerado que las mujeres que desempeñan puestos directivos o gerenciales suelen preocuparse por el bienestar de toda la organización, pues motivan y alientan lo que es catalogado como debilidad debido a que expresan sus emociones y compasión.

Las mujeres con una marcada OE buscan al dirigir un nuevo negocio, la autonomía y jornadas laborales flexibles, en donde puedan conjugar el trabajo con el ser madres de familia, sin necesidad de tener que elegir entre jugar un papel u otro. Al mismo tiempo, obtener ingresos dignos que les permite cubrir sus necesidades y mejorar tanto su calidad de vida como el de las personas que las rodean. De acuerdo con el Instituto de la Mujer Guanajuatense (IMUG) del 2018, existe una inequidad entre hombre y mujeres, en materia de percepciones, y una buena opción para las mujeres es ser emprendedoras con fuerte OE que les permita mejorar el rendimiento de sus empresas, contribuir a la producción local y generar puestos de empleo y, sobre todo, disminuir la inequidad de género. 
Asimismo, lamentablemente tanto a nivel mundial como nacional no se ha podido aprovechar al máximo todos los beneficios que las mujeres en puestos gerenciales o directivos pueden desplegar, ya que una de las problemáticas que evita que las mujeres puedan desarrollarse en dichos puestos está ligada con las diferencias de género y la presencia de estereotipos en las sociedades, que impiden que las mujeres tengan una mayor inclusión en la dirección de PYMES, debido a su "debilidad emocional", que supuestamente no les permite tomar las decisiones adecuadas para generar suficiente utilidades y un impacto socioeconómico, en la sociedad donde se localizan.

Las ventajas que puede traer el análisis del impacto de la OE y el desarrollo de sus dimensiones de la innovación, toma de riesgos, autonomía, proactividad y competencia agresiva, en el rol de la mujer gerente en el STC, en el sur del estado de Guanajuato, pueden ser muchas, pero las más significativas son: el educarse en materia de emprendimiento y que esta se traduzca en acciones como innovar, invertir, buscar nuevos mercados etc. Además, de darle seguimiento a través de la planeación estratégica y generar un impacto empresarial sustentable en la sociedad (responsabilidad social empresarial: confiabilidad del producto, cuidado del medio ambiente, pago de salarios justos, comercio justo, empleos bien remunerados de acuerdo con la productividad) (Arroyo y Cárcamo, 2010). Al mismo tiempo, permitirá que las mujeres emprendedoras del sector del vestido conozcan un modelo teórico de la OE, que les permita implementar y/o mejorar sus negocios. De igual manera, con la realización de este estudio se puede lograr que el STC en los municipios de Uriangato, Moroleón y Yuriria implementen determinadas estrategias que generen un sector más competitivo dentro del estado y el país.

El artículo está compuesto por un marco teórico, una metodología, resultados y reflexiones finales, y conclusiones y limitaciones de la investigación.

\section{Análisis Teórico}

De acuerdo con Fadda (2018) la Orientación Emprendedora (OE) es una alineación estratégica que ha estado estrechamente vinculada con el éxito empresarial mediante la toma de decisiones estratégicas, la cual debe ser implementada y conocida por todos los niveles jerárquicos de la organización. Lumpkin \& Dess (1996), Dess \& Lumpkin (2005) argumentan que la $\mathrm{OE}$ consiste en el desarrollo de las cinco dimensiones: innovación, proactividad, toma de riesgos, agresividad competitiva y autonomía que desarrolladas por las empresas, permiten un aumento en el rendimiento de las pequeñas y medianas empresas (PYMES) ( Kelly \& Zaman, 2014).

Asimismo, la OE es definida como una estrategia con procesos interrelacionados que permiten la explotación de las oportunidades, la adaptación constante de la empresa a los cambios del entorno, la renovación estratégica, la reestructuración organizacional y los ajustes a recursos y capacidades especificas (Burgelman, 1983; Álvarez \& Urbano, 2011; Busenitz, 2003; Galán \& Sánchez, 2009).

La OE sugiere que algunas actividades empresariales se desarrollen dentro de la empresa afectando las decisiones, las características, procesos, acciones y el desempeño de una organización. El constructo de $\mathrm{OE}$ proviene de la literatura de gestión estratégica y trata el proceso de elaboración de la estrategia (Fadda, 2018).

La OE surge de la alta gerencia y es tomada en cuenta en toda la organización y se sustenta con la asignación adecuada de los recursos necesarios para su desarrollo. Asimismo, las facetas de la OE están estrechamente vinculadas al esfuerzo de innovación de las empresas. Una fuerte $\mathrm{OE}$ conduce a la búsqueda de una nueva oportunidad, lo que puede llevar a la rentabilidad, pero sólo si se logra a través del éxito de la innovación (Arunachalam, Ramaswami, Herrmann, \& Walker, 2016). 
La orientación empresarial se ha convertido en uno de los conceptos más aceptados en la literatura de gestión estratégica y emprendimiento. Se define como una posición estratégica organizacional que captura los procesos, las prácticas y las actividades específicas que permiten a las empresas crear valor al participar en actividades empresariales (Raymond, Bergeron, Croteau, \& St-Pierre, 2015).

La orientación empresarial es el proceso, las estructuras y los comportamientos de las empresas que se caracterizan por su capacidad innovadora, actuación proactiva y el asumir riesgos, lo que permite a las empresas reconfigurar las capacidades internas y externas para hacer frente a los entornos que cambian rápidamente. Sin $\mathrm{OE}$, el comportamiento de la empresa no sería dinámico ni adaptativo ( $\mathrm{Li}$, Zhao, Tan, \& Liu (2008)).

Lumpkin y Dess (1996), definieron el espíritu empresarial como "nueva entrada", mientras que $\mathrm{OE}$ es un constructo innovador que describe cómo se emprende la "nueva entrada". La OE se puede lograr ingresando en un mercado nuevo o establecido con productos o servicios nuevos o innovando en los existentes y actuando ya sea por una empresa de nueva creación, una empresa existente o por medio de una empresa corporativa interna ( Zhang \& Yang 2010).

Las empresas con orientación empresarial intentan identificar y explotar nuevas oportunidades de forma persistente, crear nuevos valores y convertirse en líderes en los mercados. Según investigaciones anteriores, la orientación empresarial es un factor importante que conduce al desarrollo exitoso de nuevos productos, un alto rendimiento empresarial financiero y no financiero y un alto rendimiento social.

El emprendimiento es un nuevo negocio que se va a crear; mientras que la $\mathrm{OE}$ es el cómo se va a desarrollar, lo que se quiere crear, mediante la innovación, la proactividad, la toma de riegos, la competitividad agresiva y la autonomía. Tanto en el emprendimiento como en la $\mathrm{OE}$, el emprendedor es una pieza clave, pues es quien a través de sus innovaciones va rediseñando la forma de un mercado o la manera de operar de un producto o servicio (ver Figura $1)$.

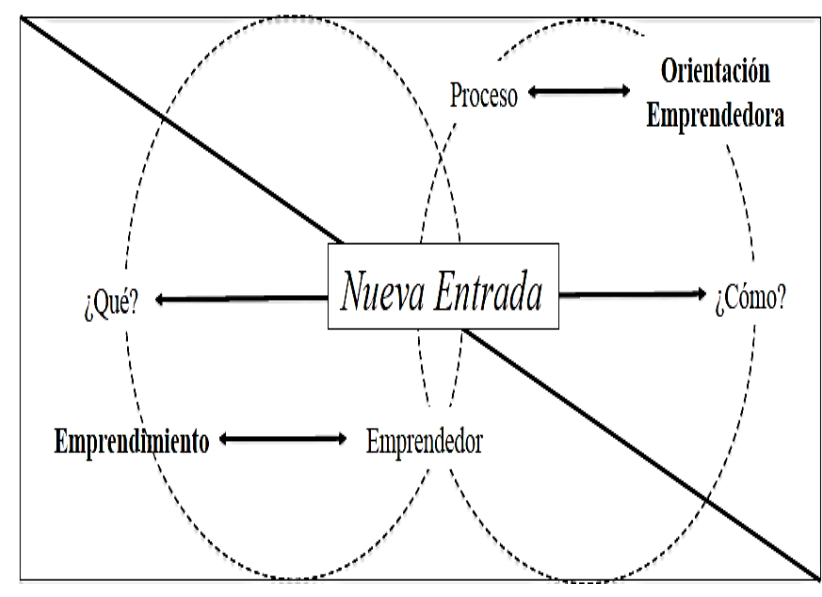

Figura 1 Diferencia entre emprendimiento y Orientación emprendedora

Fuente: Zhnag \&Yang (2010)

De acuerdo con Fernández-Mesa, Alegre-Vidal y Chiva-Gómez (2012) el emprendimiento se refiere al proceso que comprende la creación, desarrollo y renovación de una empresa, en tanto que la orientación emprendedora (OE) refiere al proceso estratégico que guía a las empresas para que realicen acciones encaminadas a bloquear $\mathrm{o}$ anticipar la competencia de su ambiente de negocio. Esta orientación emprendedora es un constructo multi-dimensional que incluye los componentes de innovación, proactividad y toma de riesgos (Covin y Slevin citado por Renko, Carsrud, y Brännback, 2009, p. 336). Si bien la capacidad emprendedora puede estar apoyada por las características de los ejecutivos, se trata de una capacidad organizacional que lleva a la empresa a actuar sobre su ambiente. Por tanto, hay que distinguirla de la orientación emprendedora del individuo (IEO, Individual Entrepreneurial Intention por sus siglas en inglés) que se refiere a las características y actitudes de un individuo que lo hacen más proclive a involucrarse en actividades de emprendimiento y que de acuerdo con la escala desarrollada y validada por Bolton y Lane (2012) incluyen tres dimensiones equivalentes a la EO y que son: innovación, toma de riesgos y proactividad. Estas características, aparte de otras características personales como la necesidad de auto-realización, la auto-confianza y el control personal, se asocian con las intenciones de emprendimiento del individuo. 


\section{Innovación}

La innovación se traduce en un comportamiento emprendedor con una importante variedad de invenciones empresariales que adquieren la forma de nuevos productos, procesos, mercados, materias primas e incluso distintas formas organizativas. Desde esta perspectiva, la orientación emprendedora se materializa tanto en la creación de nuevos recursos como en nuevas maneras de combinar los recursos con los que ya se cuenta (Ripollés \& Blesa, 2006).

La innovación empresarial se enfoca al desarrollo de procesos innovadores que resulta en la creación de nuevos productos, nuevos servicios y descubrimientos tecnológicos (Fadda, 2018). También refleja una tendencia a participar y apoyar nuevas ideas, innovación, experimentación y procesos creativos (Hormiga, de Saá-Pérez, Díaz-Díaz, BallesterosRodríguez, \& Aguiar-Diaz, 2017).

La innovación es la aplicación de ideas creativas y originales y realización de procesos de diligencia procedente, cómo producir nuevos productos, nuevos procesos, nuevos desarrollos de proveedores y recursos naturales. La capacidad de innovación es componente crítico del espíritu empresarial que sostiene los valores que las empresas desean, al realizar nuevos cambios o combinaciones mediante ideas creativas (Cho \& Lee, 2018).

\section{Proactividad}

La proactividad se define como un proceso organizativo de búsqueda de nuevas oportunidades de negocio y la optimización de la tenencia de recursos. Los empresarios estén constantemente observando el entorno para poder identificar nuevas oportunidades emprendedoras y capitalizarlas antes que la competencia (Ripollés \& Blesa, 2006). La actividad proactiva es una postura de anticipar y actuar sobre los deseos y necesidades futuros de la demanda en el mercado, creando así una ventaja frente a los competidores (Hormiga et al., 2017). También es la acción independiente de un individuo o equipo cuyo objetivo es dar a conocer un concepto o visión de negocio y culminarlo (Andrade-Valbuena, MerigoLindahl, \& Olavarrieta, 2018).

\section{Toma de Riesgos}

La OE se vincula con las decisiones estratégicas de tomar riesgos de moderados a elevados, cuya aceptación en la toma de decisiones empresariales es inevitable en comportamientos innovadores y proactivos (Ripollés \& Blesa, 2006). La toma de riesgos está vinculada con la inclinación de la empresa a emprender actividades riesgosas en medio de la incertidumbre como la exposición a deudas e inversiones riesgosas (Fadda, 2018).

\section{Competitividad agresiva}

La competitividad se refiere a la actitud de la empresa hacia el trato con los competidores. Consiste en monitorear y contrarrestar continuamente las estrategias de los rivales (incluso imitando a otras empresas) con el objetivo de lograr una ventaja competitiva y un mejor rendimiento (Fadda, 2018).

La competitividad agresiva es la intensidad del trabajo empresarial para superar a sus competidores, estando en contacto con el entorno e identificar y satisfacer las necesidades de los clientes, logrando tener una mayor participación en el mercado, en comparación con sus competidores, trabajando en ser innovadores, proactivos $\mathrm{y}$ asumir riesgos (Bolton, 2012).

\section{Autonomía}

La autonomía es la acción independiente, emprendida por líderes o equipos empresariales para generar una nueva empresa y lograr su consolidación. También se refiere a la capacidad de las organizaciones para emprender $y$ desarrollar nuevos productos o servicios de manera autónoma (Bolton, 2012). La autonomía aborda el desarrollo y la posterior implementación de ideas innovadoras. Una cultura organizacional que promueva nuevas iniciativas sin frenar la creatividad individual podría considerarse autónoma (Fadda, 2018).

Los resultados empíricos de estudios anteriores también promueven que las empresas no tienen necesariamente todas las dimensiones de OE alta o baja al mismo tiempo. La tendencia de riesgo de una empresa puede variar dependiendo de la duración de su actividad. 
La actividad de una empresa en términos de cada dimensión parece variar en relación con la etapa de la empresa, el tipo de producción o servicio y el entorno, definiéndose la OE como enfoque multidimensional, que bien puede proporcionar detalles adicionales sobre el origen de la OE y la influencia de cada dimensión en el desempeño de la empresa (Fadda, 2018).

La implementación de la OE en las organizaciones puede ser muy beneficiosa, al desarrollar una ventaja competitiva frente a la competencia, debido a que requiere tener un acercamiento con los clientes para poder conocer qué es lo que quieren o qué es lo que necesitan y de esta forma satisfacerlos, generando la fidelidad de este. Contribuye así mismo a la transformación organizacional y renovación estratégica. La OE supone que dentro de la empresa se tiene que compartir el conocimiento, pues no solamente este constructo debe conocerlo la alta gerencia, sino todos los niveles que la componen, para lograr como resultado un mejor rendimiento en las pequeñas y medianas empresas (Fan, Le, Sheng, \& Zhang, 2012).

\section{Revisión de la literatura: El emprendimiento femenino y la OE}

Ahora bien, dentro de los estudios sobre OE con un enfoque de género se tiene una investigación realizada en las tres principales ciudades de Ghana (Accra, Kumasi y Takoradi) para conocer el impacto que tiene el rol de la mujer en la $\mathrm{OE}$ y éste reveló que efectivamente las mujeres tienen una relación positiva entre EO y el desempeño organizacional y esta relación esta mediada por la motivación y los factores de impulso (Adams, Quagrainie, \& Klobodu, 2017). De igual manera, en la India se llevó a cabo una investigación para evaluar la OE desde un punto de la personalidad y la actitud de los recursos humanos, esta aportó como resultado que la edad, menores calificaciones educativas y un alto estatus socioeconómico apoyaban el espíritu empresarial de las mujeres (Kundu \& Rani, 2016).
También hay estudios en relación con la OE de las mujeres, en este caso hay una investigación realizada en Ghana en donde entrevistaron a 286 mujeres empresarias para examinar la relación entre OE y desempeño organizacional. El principal objetivo era analizar si la motivación mide la relación entre el desempeño y la organización. Para poder llevarla a cabo se utilizó una técnica de estimación de modelos de ecuaciones estructurales. Los hallazgos indican una relación positiva entre OE y el desempeño organizacional. De igual manera, dentro de las dimensiones de la OE se encontró que la proactividad y la competitividad agresiva muestran una relación positiva con el desempeño organizacional, también la OE está relacionada con las medidas no financieras. De igual manera, la relación entre $\mathrm{OE}$ y el desempeño organizacional esta mediada por la motivación y los factores de impulso (Adams, Quagrainie, \& Klobodu, 2017).

Hay tres modelos que ayudan a explicar las estructuras de negocios empleadas por mujeres en sus negocios. El modelo del río del tiempo encuentra que las dos fuerzas de preocupación por las mujeres son los logros profesionales $\mathrm{y}$ personales $\mathrm{y}$ las relaciones familiares $y$ personales. El modelo de perspectiva integrado resalta el poder de las relaciones que integran la vida personal y profesional. La Teoría de la Proyección sugiere que las personas se esfuerzan por lograr ciertas circunstancias de manera que sean coherentes con sus propias necesidades, temores, inquietudes, impulsos, conflictos y formas de percepción. Los elementos comunes en los tres enfoques ayudan a explicar por qué las mujeres son propietarias y proporcionan información consistente con sus propios valores y emplean una ética de justicia (States, \& States, 2004).

Aun cuando las mujeres tienen más posibilidades de convertirse en empresarias, poseen empresas más pequeñas y menos desarrolladas que los hombres. Las empresas de las mujeres tienen opciones de negocio más limitadas, debido a la falta de oportunidades de acceso a educación, capacitación, habilitación técnica y fuentes de financiamiento, entre otros aspectos. La mitad de la población femenina que trabaja por su cuenta es empleadora y se concentra en el sector terciario (comercio y servicios). 
De igual manera, dentro de los indicadores sociodemográficos que han influido en estos tiempos a que las mujeres tengan una mayor tendencia al emprendimiento están: el aumento de la esperanza de vida, mayores niveles de escolaridad, la disminución de las tasas globales de fecundidad y el alargamiento de su vida económicamente activa. Estos elementos han contribuido a despertar en muchas mujeres, el interés por desarrollar una actividad productiva, como parte de su autonomía personal y de su proyecto de vida (Compean, Belausteguigoitia, \& Navarrete, 2015).

Los factores que caracterizan a las mujeres que deciden emprender una empresa, presentan características que les permiten dirigir las actividades de manera eficiente para alcanzar el éxito de su empresa. A continuación, se presentan las características que deben presentar las mujeres que deciden emprender una empresa (Figura 2).

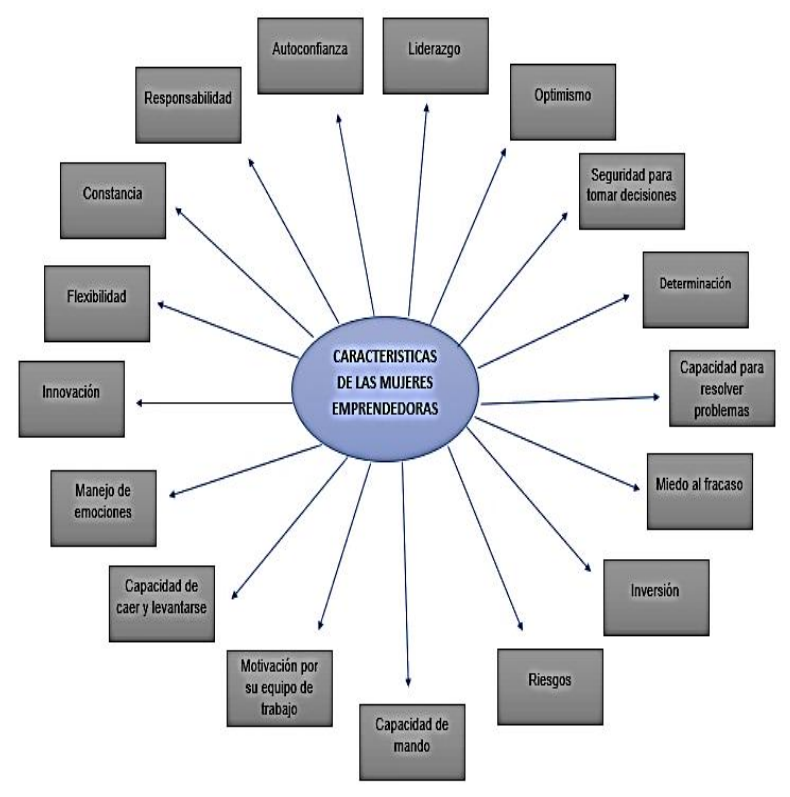

Figura 2 Características de las mujeres emprendedoras Fuente: García Vences \& Plata García (2017)

La mujer a lo largo de la historia ha sido un personaje que ha tenido que luchar por lograr ser tomada en cuenta en la sociedad y hacer valer sus derechos como todo ser humano. En el mundo y no sólo en México, la mujer ha tenido complicaciones para poder llegar a ocupar el papel que en la actualidad tiene. Si nos remontamos a años atrás, podemos darnos cuenta de que sólo se consideraba a la mujer apta para ser ama de casa, cuidar a los hijos y de su cónyugue, creando así una imagen domesticada de las mujeres.
Para cambiar este paradigma, la mujer ha tenido que cambiar y viene conquistando su lugar en la sociedad y, por consiguiente, su rol como empresaria al contribuir al desarrollo social y económico de una sociedad (Cultura, Breno, Ribeiro, Helena, \& Sanches, .2000).

Las mujeres cuentan con ciertas características cualitativas al momento de ocupar puestos en altos mandos en el mundo laboral. Por ejemplo, tienen una mayor tendencia a expresar sus emociones, también se preocupan por el bienestar de todo el equipo de trabajo y, para ello, implementan la motivación. Asimismo, las empresarias son democráticas y participativas (Cultura, Breno, Ribeiro, Helena, \& Sanches, .2000).

Las mujeres a menudo inician un negocio como una forma de ganar más control sobre su equilibrio en el trabajo y en su vida. Comenzar un negocio proporciona a algunas mujeres más flexibilidad e independencia en su vida laboral. Además, ha aumentado el interés en que las mujeres inicien negocios, especialmente cuando están criando a sus hijos. Estas mujeres han sido referidas como "mompreneurs" (Korsgaard, 2007), ya que no sólo son madres, sino también empresarias. Las emprendedoras pueden generar ingresos para su familia, mientras manejan la carrera y la maternidad. Esto está cambiando el papel de las mujeres en el mercado laboral, debido al aumento en el número de mujeres con hijos que tienen un empleo a tiempo parcial. Asimismo, hay factores de atracción y empuje que influyen en la formación de las empresarias.

Los factores de atracción normalmente se centran en la necesidad de ganar dinero, lo que obliga a las mujeres a iniciar su propio negocio. Otros factores de atracción incluyen el aburrimiento o querer un cambio. Por otro lado, los factores de impulso se relacionan más con el reconocimiento de oportunidades y luego el inicio de un negocio. Las empresarias tienden a ser más jóvenes y educadas. Más mujeres son atraídas hacia el espíritu empresarial debido al aumento de la condición social de ser empresarias. Además, algunas mujeres ven el comenzar un negocio, como una manera de tener independencia financiera. El espíritu empresarial ayuda a las mujeres a encontrar su propia identidad profesional y les da un reconocimiento en la fuerza laboral (Ratten \& Tajeddini, 2018).

CÁRCAMO-SOLIS, María de Lourdes, DÍAZ-ZAMUDIO, Mayra Joceline y ARROYO-LÓPEZ, María del Pilar. La orientación emprendedora femenina en la industria textil y de la confección, en Moroleón, Guanajuato, México. Revista de Desarrollo Económico. 2020 
De acuerdo con datos de la Organización y Cooperación y Desarrollo Económico (OCDE) muchas mujeres mexicanas se enfrentan a importantes obstáculos que les impiden participar plenamente en el mercado laboral. Estos incluyen: la carga del trabajo no remunerado (las mexicanas dedican 4 horas diarias más al trabajo no remunerado); los tradicionales roles de género; y la carencia de políticas de conciliación entre trabajo y vida familiar, especialmente la insuficiente oferta de servicios de cuidado infantil y de prácticas laborales flexibles. De igual manera, las mujeres ocupan el $31 \%$ de los puestos de alta dirección en México (32\% en la OCDE), $7 \%$ de los miembros de la junta directiva de las empresas mexicanas son mujeres (10\% en la OCDE), y sólo el $2 \%$ de las mujeres mexicanas son empresarias (en comparación con el 6\% de los hombres).

Las mujeres ocupan menos de un tercio de los puestos gerenciales y tienen una participación de 1a mujer por cada 10 hombres en los puestos directivos y dentro del mundo empresarial de estas, sólo el $2 \%$ de las mujeres trabajadoras son emprendedoras contra el 6\% de los hombres. De igual forma, es muy importante destacar, que, según datos de Secretaría de Hacienda y Crédito Público, en el año 2013 de cada cinco pequeñas y medianas empresas que se abren tres están lideradas por mujeres y de cada 100 mujeres que solicitan un préstamo para invertir en su empresa, el 99\% salda sus deudas de manera íntegra.

De igual manera, es importante destacar que las mujeres empresarias o que se encuentran dentro del mercado laboral llevan a cabo algunas estrategias para poder permanecer o ingresar a un puesto gerencial y/o directivo (Camarena, 2007). Algunas estrategias que implementan son las siguientes:

Saber qué es lo que se espera de ella en un puesto para no imaginar lo que se pide.

- $\quad$ Ser objetiva y eficiente.

- Conocer sus habilidades y tener la capacidad de aprovechar las oportunidades que se presentan, es más, propiciar que se den.

Perseverancia y lealtad.
Las mujeres empresarias son participativas, desarrollan un estilo femenino, otorgan un gran valor a la comunicación interpersonal, se apoyan al momento de dirigir de acuerdo con el concepto de cooperación, fomentan el trabajo en equipo, buscan mayor participación y delegan más. Tienen una estrategia empresarial orientada a la organización y las relaciones laborales, más que, a las innovaciones tecnológicas, son creativas, visionarias, tolerantes, con capacidad de planificación, determinación, liderazgo, flexibilidad y seguridad (Compean, Belausteguigoitia \& Navarrete, 2015).

De acuerdo, con un listado que realizó el portal de avisos de empleos Bumeran, las mujeres que se postulan a puestos altos en las empresas forman el $30 \%$, las que se postulan a un puesto medio $27 \%$ y para puestos de analistas $42 \%$. De igual manera, las mujeres tienen mayor oportunidad laboral en las siguientes áreas:

- $\quad$ Administración, contabilidad y finanzas.

- Comercial y ventas.

- Recursos humanos y capacitación.

- $\quad$ Salud, medicina y farmacia.

- $\quad$ Educación, docencia e investigación.

- Secretarias o recepción.

- $\quad$ Marketing y publicidad.

Abastecimiento y logística.

Comunicación, relaciones institucionales y públicas.

\section{Objetivo e hipótesis de investigación}

El objetivo del presente trabajo de investigación se centra en analizar cómo el papel de la mujer en la gerencia y/o dirección en las Pymes del STC, en los municipios de Uriangato, Moroleón y Yuriria, pertenecientes a la región sur del estado de Guanajuato, se manifiesta en las cinco dimensiones de la Orientación Emprendedora. 
Las hipótesis de trabajo son:

$\mathrm{H}_{1}$ : El rol de la mujer en la gerencia y/o dirección en el STC, en la región sur del estado de Guanajuato se manifiesta positiva y significativamente en la innovación.

$\mathrm{H}_{2}$ : El rol de la mujer en la gerencia y/o dirección en el STC, se manifiesta positiva y significativamente en la toma de riesgos.

$\mathrm{H}_{3}$ : El rol de la mujer en la gerencia y/o dirección en el STC, se manifiesta positiva y significativamente en la proactividad.

$\mathrm{H}_{4}$ : El rol de la mujer en la gerencia y/o dirección en el STC, se manifiesta positiva y significativamente en la autonomía.

$\mathrm{H}_{5}$ : El rol de la mujer en la gerencia y/o dirección en la STC, se manifiesta positiva y significativamente en la competitividad agresiva.

\section{Antecedentes del Sector Textil y de la Confección}

El STC fue un sector de gran importancia en el siglo XIX, ya que fue el detonador del incipiente sistema capitalista. En la actualidad, la industria textil en México atraviesa por una crisis que ha sido provocada por la falta de competitividad en los mercados internacionales, la insuficiencia de políticas comerciales e industriales y la escasa diversificación de producción en todos los segmentos de la cadena hilo-textil -confección.

En el caso particular del clúster textil y de la confección del Sur de Guanajuato (comprendido por Moroleón, Uriangato y Yuriria) (ver Figura 3) tuvo sus inicios en los años 80's con la fabricación de suéter. Para el año de los 90, se estimaba que existían entre 200 y 250 talleres de suéter en donde la totalidad de su producción era destinada al consumo nacional y en este año también se dan las primeras exportaciones para clientes estadounidenses y canadienses. A partir del año 2000 hasta la fecha, la industria textil y su comercialización se ha visto afectada por la entrada de materias primas y prendas de vestir con procedencia de países como China, India, Corea, Indonesia y Taiwán; las cuales se caracterizan por tener ventajas absolutas en el bajo costo de mano de obra y el costo energético (Razo, 2017).

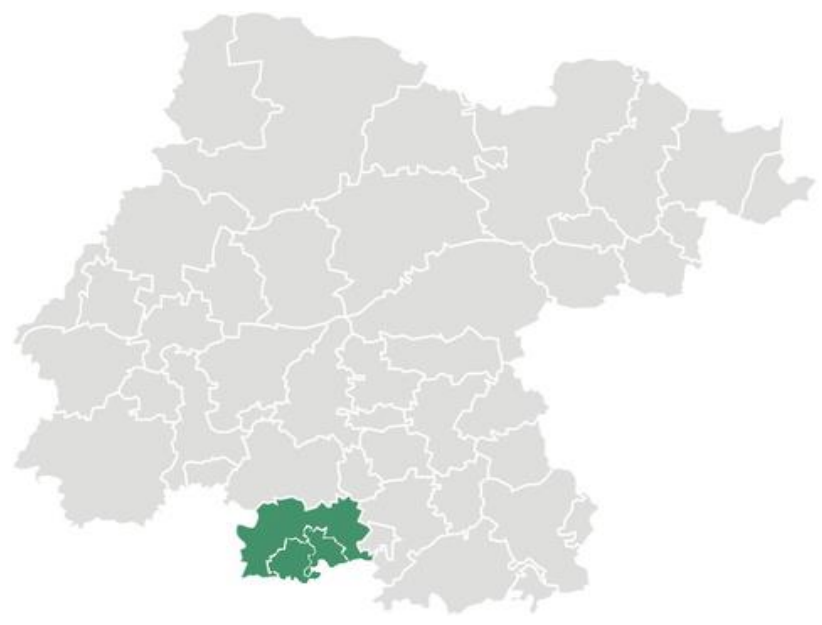

Figura 3 Localización del Clúster Textil y de la Confección, en la zona metropolitana de Moroleón, Uriangato y Yuriria

Fuente: Obtenido de mapas de Google

La historia de la industria textil en la zona metropolitana del Sur de Guanajuato tiene sus inicios en el año de 1815, en este tiempo ya se encontraban algunos pobladores dedicados a la elaboración de algunas prendas de vestir especialmente el reboso. Y fue en el mismo año, cuando el Padre Torres incendio todo el poblado de Yuriria para evitar que las guerras o los saqueos de esos tiempos perjudicaran a los comerciantes. Lamentablemente, dicha situación solo ocasionó que los comerciantes huyeran a lo que hoy en día se conoce como los municipios de Uriangato y Moroleón. Fue así como se inició una actividad comercial en grande. atrayendo vendedores y compradores de otros lugares. Con ello, se establecieron diversos talleres de reboso.

Durante 1842 a 1846 se comenzaba a vender las prendas en otros lugares como la Ciudad de México y Puebla, ya para el siglo XIX, el comercio asumió dos maneras de llevarlo a cabo; una de ellas era a través de pequeñas tiendas o establecimientos y la otra por el comercio exterior el cual se realizaba en las plazas o calles de los poblados a los que iban a vender los productos.

Para el siglo $\mathrm{XX}$, en dichos municipios llegaron las máquinas de coser las cuales ayudaron a que el trabajo y los productos se hicieran de una forma más eficaz y reducir los tiempos de producción. 
Asimismo, en dichos municipios se buscaban acciones que contribuyeran a un mayor desarrollo y crecimiento del sector, por ello el día de hoy se encuentran escuelas como el Tecnológico Superior del Estado de Guanajuato ubicado en Uriangato y el Conalep ubicado en Moroleón, que fueron instaladas para ofrecer a la población carreras o talleres que contribuyan al fortalecimiento de los conocimientos de los empresarios de la región.

Lamentablemente, con la globalización muchos de los negocios de los municipios de Yuriria, Uriangato y Moroleón se volvieron obsoletos e incluso muchos de ellos tuvieron que cerrar, debido a la falta de innovación. Al mismo tiempo, otro factor que daño drásticamente a la industria del vestido en la región sur fue la entrada de nuevos competidores como China que puede competir con su bajo costo en el mercado, lo que generó que los consumidores prefirieran los productos chinos por su costo que los productos de los vendedores de la región. Para poder atacar dicha problemática, los empresarios tuvieron que recurrir a medidas drásticas para lograr que sus prendas fueran vendidas, por ejemplo, bajaron la calidad de sus productos y se malbarató la mano de obra lo cual afecto en gran medida a la población.

El día de hoy la región metropolitana del sur de Guanajuato ha buscado nuevas estrategias para lograr que el STC vuelva a consolidarse y tener mayor demanda no solo a nivel nacional, sino también impulsar que mayores empresarios se decidan a exportar sus productos, ampliando con ello los mercados, es por ello que el gobierno a través de sus instituciones como Coordinadora de Fomento al Comercio Exterior (COFOCE), buscan orientar a los empresarios para que puedan exportar sus productos y que éstos cumplan con los requisitos de estándares de calidad, confiabilidad, diseño y marca exclusivas, uso de materias primas de menor impacto al medio ambiente y confiables y útiles al consumidor.

Otra de las estrategias que están implementando en esta zona son la creación de la Plaza Textil Metropolitana ubicada entre Uriangato y Moroleón, la cual tiene el objetivo de atraer a clientes que busquen comprar principalmente a mayoreo.
Al mismo tiempo, lo que buscaban dichos municipios es brindar una mayor comodidad a los consumidores para que no tengan que caminar por toda "La Famosa Calle de la Ropa" (como usualmente se le conoce), sino que en un mismo lugar puedan encontrar los artículos que buscan, alimentos, baños y estacionamiento en donde puedan estar seguros.

Al mismo tiempo, en un trabajo colaborativo los municipios de Uriangato y Moroleón han implementado un Centro de Inteligencia en Vestido y Moda de Guanajuato (VEMOG), el cual tiene como principal objetivo brindar capacitación, asistencia técnica y desarrollo de competencias, pues el sector textil es muy importante en esta región ya que genera el $45 \%$ de los empleos. Este centro se encuentra ubicado en el municipio de Moroleón y su principal función es contribuir a mejorar los estándares que en la industria se tienen y mejorar la competitividad; desarrollando diversas actividades como: programas de capacitación en diseño, corte, tejido, confección, tejido de punto, acabado, programación de máquinas y sobre todo brindar entrenamiento, consultoría y diseño. El VEMOG puede ser clave para que las empresas sobre todo las Pymes puedan desarrollarse y obtener ventajas competitivas que les permitan continuar en los mercados locales, nacionales e inclusive internacionales.

El sector textil de la zona metropolitana del Sur de Guanajuato cuenta con una cadena productiva, la cual es la siguiente:

- $\quad$ Producción de lienzos y telas continuas.

- Confección.

- Estampado- sublimación.

- $\quad$ Bordado electrónico.

- $\quad$ Proveeduría (mercería, equipos, etc.).

Servicios (programación de equipos electrónicos, técnicos, asesoría, etc.). 


\section{Metodología}

La presente investigación, es un estudio de naturaleza cuantitativa exploratoria, así como observacional, debido a que se pretendió describir el fenómeno, sin intervenir las variables que determinan el proceso de investigación (Hernández-Sampieri, FernándezCollado, Baptista-Lucio, 2010). Se aplicó el método de Ecuaciones Estructurales (por sus siglas en ingles SEM), para probar las hipótesis de investigación que relacionan la OE y las cinco dimensiones en cuestión.

Se optó por implementar SEM-PLS, siendo un enfoque alternativo, robusto y más flexible a los métodos tradicionales, dándoles un mayor nivel de confianza a la investigación pues permite examinar simultáneamente una serie de relaciones de dependencia entre variables independientes y dependientes (Martínez, \& Fierro, E. 2017). Además, este método permite trabajar con datos faltantes dando con ello la solución óptima (Vargas, 2019).

Se manejaron datos de tipo transversal, en razón al periodo y secuencia del estudio, para ello, se aplicó una encuesta validada por Álvarez (2019) ajustada a 18 ítems. En dicho instrumento se utilizó una escala de Likert del 1 a 7, siendo:

\section{1= Estoy fuertemente en desacuerdo.}

7= Estoy fuertemente de acuerdo.

La aplicación del cuestionario (Álvarez, 2019) se realizó usando los formularios de Google y se aplicó a 103 mujeres emprendedoras del sector textil y de la confección (STC), seleccionadas por conveniencia. La muestra fue no probabilística intencional, debido a que se requería obtener el mayor número de emprendedoras que forman una PYME y grande empresa.

El tiempo promedio que tomó a cada mujer responder a la encuesta fue de 20 minutos, sin inducir ninguna respuesta, siendo una intervención espontánea, en una oficina con ambiente agradable y propicio para la aplicación de la encuesta validada (Álvarez, 2019).
Las respuestas de las mujeres empresarias fueron en su mayoría 1 y 7 , para poder trabajar se asignó 0 al 1 y 1 al 7, trabajando un modelo binario. Pérez (2005) señala que, al utilizar una función logística, a un modelo binario se le puede aplicar el logaritmo natural para una mejor interpretación. Se trabajó bajo mínimos cuadrados ordinarios (MCO), ya que se emplea la técnica de máxima verosimilitud para estimar los coeficientes $\beta$. No obstante, Greene (2000) y Maddala (2001) argumentan que la ventaja de un modelo de tipo binario sobre un modelo de probabilidad lineal es que las probabilidades estimadas del primero pueden están fuera del rango 0 a 1 , mientras que las probabilidades arrojadas por el segundo no pueden salir del rango.

En cuanto al desarrollo de la escala, se usaron 3 items para innovación, 3 ítems para toma de riesgos, 3 items para toma de riesgos, 3 ítems para proactividad, 6 ítems para autonomía y 3 items para competitividad agresiva (Tabla 1)

\begin{tabular}{|c|c|c|}
\hline Dimensión & Ítem & Significado \\
\hline \multirow[t]{3}{*}{ Innovación (IN) } & IN1 & $\begin{array}{l}\text { En la empresa, } \\
\text { introducimos activamente } \\
\text { mejoras e innovaciones. }\end{array}$ \\
\hline & IN2 & $\begin{array}{l}\text { Nuestra empresa es creativa } \\
\text { en sus métodos de } \\
\text { operación. }\end{array}$ \\
\hline & IN3 & $\begin{array}{l}\text { Nuestra empresa está en } \\
\text { constante búsqueda acerca } \\
\text { de nuevas formas de hacer } \\
\text { el trabajo. }\end{array}$ \\
\hline \multirow[t]{3}{*}{$\begin{array}{l}\text { Toma de } \\
\text { Riesgos (RT) }\end{array}$} & RT1 & $\begin{array}{l}\text { El concepto de "tomador de } \\
\text { riesgos" es considerado un } \\
\text { atributo positivo para gente } \\
\text { en nuestra empresa. }\end{array}$ \\
\hline & RT2 & $\begin{array}{l}\text { La gente en nuestra empresa } \\
\text { está motivada a tomar } \\
\text { riesgos calculados con ideas } \\
\text { nuevas. }\end{array}$ \\
\hline & RT3 & $\begin{array}{l}\text { Nuestra empresa enfatiza } \\
\text { tanto la exploración como la } \\
\text { experimentación } \\
\text { oportunidades en el } \\
\text { mercado. }\end{array}$ \\
\hline \multirow[t]{3}{*}{$\begin{array}{l}\text { Proactividad } \\
\text { (PR) }\end{array}$} & PR1 & $\begin{array}{l}\text { Siempre intentamos tomar } \\
\text { la iniciativa en cada } \\
\text { situación (sea r con } \\
\text { competidores, proyectos } \\
\text { con otros socios o } \\
\text { proveedores). }\end{array}$ \\
\hline & PR2 & $\begin{array}{l}\text { Sobresalimos entre nuestros } \\
\text { competidores por la } \\
\text { detección de oportunidades. }\end{array}$ \\
\hline & PR3 & $\begin{array}{l}\text { Iniciamos acciones a las } \\
\text { cuales otras organizaciones } \\
\text { del ramo responden más } \\
\text { tarde. }\end{array}$ \\
\hline
\end{tabular}

CÁRCAMO-SOLIS, María de Lourdes, DÍAZ-ZAMUDIO, Mayra Joceline y ARROYO-LÓPEZ, María del Pilar. La orientación emprendedora femenina en la industria textil y de la confección, en Moroleón, Guanajuato, México. Revista de Desarrollo Económico. 


\begin{tabular}{|c|c|c|}
\hline Autonomía (AT) & AT1 & 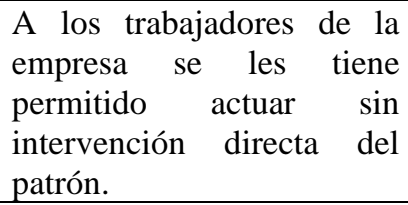 \\
\hline & AT2 & $\begin{array}{l}\text { A los trabajadores de la } \\
\text { empresa se les permite } \\
\text { investigar y desarrollar } \\
\text { mejoras en la forma en la } \\
\text { que ejecutan sus tareas } \\
\text { cotidianas. }\end{array}$ \\
\hline & AT3 & $\begin{array}{l}\text { A los trabajadores de la } \\
\text { empresa se les otorga } \\
\text { libertad e independencia } \\
\text { para decidir por sí mismos } \\
\text { acerca de cómo están } \\
\text { realizando sus actividades. }\end{array}$ \\
\hline & AT4 & $\begin{array}{l}\text { A los trabajadores de la } \\
\text { empresa se les es conferida } \\
\text { libertad para comunicarse } \\
\text { sin interferencia alguna. }\end{array}$ \\
\hline & AT5 & $\begin{array}{l}\text { A los trabajadores les es } \\
\text { conferida autoridad y } \\
\text { responsabilidad para actuar } \\
\text { por sí mismos, si que ellos } \\
\text { piensen que están } \\
\text { protegiendo los intereses de } \\
\text { la empresa. }\end{array}$ \\
\hline & AT6 & $\begin{array}{l}\text { A los trabajadores de la } \\
\text { empresa se le otorga acceso } \\
\text { a toda la información vital } \\
\text { del negocio. }\end{array}$ \\
\hline $\begin{array}{l}\text { Competitividad } \\
\text { Agresiva (CA) }\end{array}$ & CA1 & $\begin{array}{l}\text { Nuestra empresa es } \\
\text { intensamente competitiva. }\end{array}$ \\
\hline & CA2 & $\begin{array}{l}\text { En general, en nuestra } \\
\text { empresa se toma un } \\
\text { agresivo acercamiento con } \\
\text { los competidores del } \\
\text { mercado. }\end{array}$ \\
\hline & CA3 & $\begin{array}{l}\text { En la empresa tratamos de } \\
\text { desarticular y dejar fuera a } \\
\text { la competencia del } \\
\text { mercado. }\end{array}$ \\
\hline
\end{tabular}

Tabla 1 Cuestionario validado Fuente: Adaptado con base a Álvarez (2019)

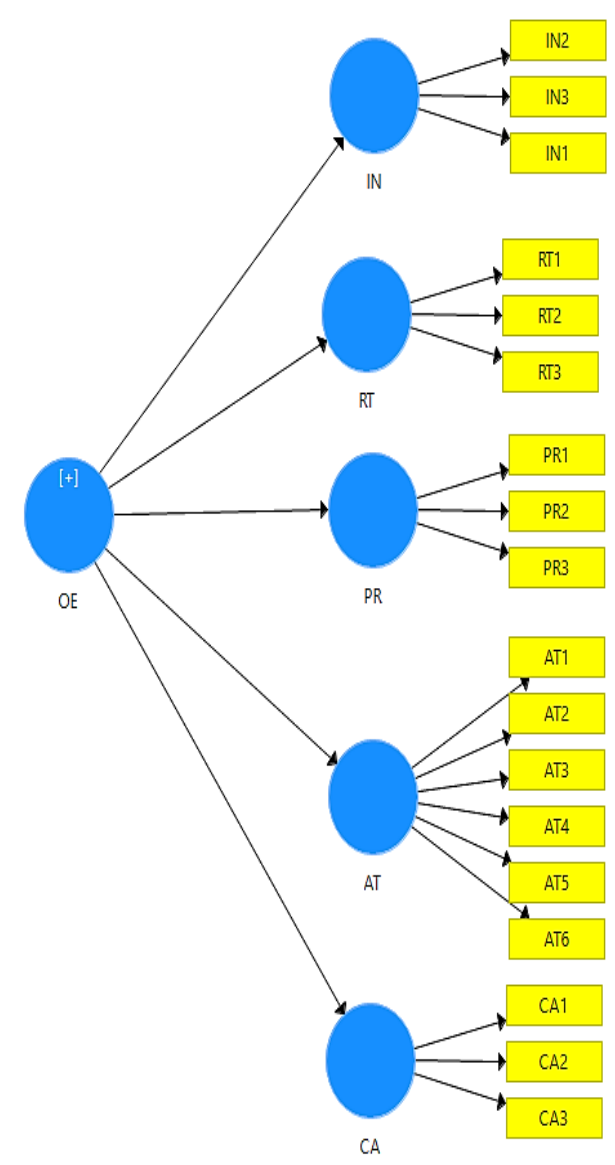

Figura 4 Modelo Teórico

De las 103 mujeres que se encuestaron el $44.6 \%$ tienen edades entre16 a 25 años, $27.1 \%$ están en el grupo de edad 26 a 35 años, $14.5 \%$ de 36 a 45 años y finalmente $13.5 \%$ al de 46 a 60 años. Siendo el primer grupo el mayor, indicando que las mujeres desde temprana edad pueden acceder a un puesto de gerente o encargada en algún negocio textil. En cuanto al nivel académico de las mujeres en el STC, el 9.7\% culminaron la primaria, $29.1 \%$ terminaron la secundaria, $34 \%$ la preparatoria, $26.2 \%$ la universidad y el $1 \%$ cuenta con algún posgrado.

El mayor porcentaje se encuentra en mujeres que completaron la secundaria, por lo cual dentro del SCT no es muy importante en la región de estudio el contar el contar con un grado alto de estudios para poder ocupar algún puesto de gerente o tener un negocio propio. De las mujeres estudiadas, el $47.6 \%$ son solteras, el $45.6 \%$ son casadas y $6.8 \%$ son divorciadas, por lo que se puede decir, que, con el paso de los años, cada vez, más mujeres solteras prefieren establecer su propio negocio o tienen mayor oportunidad de ocupar algún puesto gerencial en el mismo STC. 
De acuerdo con el lugar de origen, $53.4 \%$ son de Uriangato, $36.9 \%$ Moroleón y el $9.7 \%$ son mujeres de Yuriria.

El tamaño de las empresas o negocios que las mujeres encuestadas dirigen, $43.7 \%$ son microempresas, $35.9 \%$ son pequeñas, $16.5 \%$ son medianas y solamente el 3,9\% corresponde a empresas grandes, en la región Sur de Guanajuato.

Dentro de los hallazgos cualitativos que se pudieron observar en el trabajo de campo destacan los siguientes:

- $\quad$ Las mujeres gerentes en el STC no pueden tomar decisiones importantes sobre la empresa que lideran, sin antes consultarlo con el dueño de esta.

- $\quad$ Las mujeres con puestos altos, en el STC buscan aumentar la cartera de clientes y aplican estrategias que ayuden a incrementar las ventas de los negocios que lideran.

Al mismo tiempo, es importante resaltar que dentro del STC, es más sencillo que las mujeres puedan llegar a ocupar algún puesto de alto mando en una empresa, ya que los requisitos de estudios no son obligatorios y se considera en mayor medida la experiencia que éstas tengan, otorgándoles la capacitación por parte de los dueños de los negocios para que puedan desempeñar las tareas y actividades que el puesto de gerente exige.

\section{Resultados y Conclusiones}

El primer paso del análisis de datos fue determinar el grado de confiabilidad general de las variables usadas para medir la $\mathrm{OE}$, siendo un Alfa de Cronbach de 0.731, indica que el constructo tiene una confiabilidad alta, por lo que nuestro constructo es fiable y tiene consistencia interna.

Como consecuencia de lo anterior, se procedió a la obtención de dos criterios más, que, de igual manera, contribuyen a verificar que el modelo propuesto tenga fiabilidad. Se calculó el Análisis de la Varianza Explicada (AVE) la cual debe ser mayor a 0.70 para poder aceptar el modelo, por lo que cuenta con fiabilidad pertinente.
Así mismo las variables latentes que componen la OE también tienen una confiabilidad interna mayor a 0.7 generando un modelo robusto y más flexible a los métodos tradicionales, dándole un mayor nivel de confianza a la investigación (Tabla 2).

\begin{tabular}{|l|c|}
\hline & A VE \\
\hline Autonomía & 0.806 \\
\hline Competitividad Agresiva & 0.759 \\
\hline Innovación & 0.777 \\
\hline Proactividad & 0.799 \\
\hline Toma de Riesgos & 0.748 \\
\hline
\end{tabular}

Tabla 2 Análisis de la Varianza Explicada Fuente: Elaboración propia con datos de la encuesta

Asimismo, se aplicó el Criterio de Fornell para confirmar la fiabilidad del modelo de medida. Y al momento de la aplicación para cada una de las variables se obtuvieron puntuaciones con valores aceptables (Tabla 3 ).

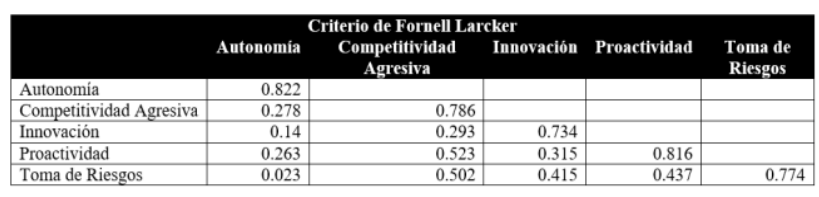

Tabla 3 Criterio de Fornell Larcker

Fuente: Elaboración propia con datos de la encuesta

La tabla 4 nos muestra los resultados del modelo SEM PLS, aprobando todas las hipótesis, se utilizaron los coeficientes la $\mathrm{T}$ de Student y los coeficientes $\beta$. Es por ello, que en todas nuestras variables latentes obtuvieron valor de $\mathrm{p}<0.001$ lo que quiere decir que $\mathrm{H}_{1}, \mathrm{H}_{2}$, $\mathrm{H}_{3}, \mathrm{H}_{4}$ y $\mathrm{H}_{5}$ cuentan con respaldo empírico.

\begin{tabular}{|l|l|l|l|l|}
\hline Hipótesis & B & T & p & Criterio \\
\hline $\mathrm{H}_{1}$ & 0.673 & 6.527 & 0.000 & Aceptada \\
\hline $\mathrm{H}_{2}$ & 0.731 & 9.992 & 0.000 & Aceptada \\
\hline $\mathrm{H}_{3}$ & 0.770 & 15.355 & 0.000 & Aceptada \\
\hline $\mathrm{H}_{4}$ & 0.40 & 2.689 & 0.007 & Aceptada \\
\hline $\mathrm{H}_{5}$ & 0.775 & 18.585 & 0.000 & Aceptada \\
\hline
\end{tabular}

Tabla 4 Resultados del SEM PLS

Fuente: Elaboración propia con datos de la encuesta

$\mathrm{Al}$ aceptar las cinco hipótesis, se puede decir que, el rol de la mujer en la gerencia y/o dirección en el STC de la región sur del estado de Guanajuato, se manifiesta positiva y significativamente en la Orientación Emprendedora, ya que se cumplieron satisfactoriamente todas las hipótesis que se plantearon en este estudio. 
Después de haber concluido que nuestro modelo tiene fiabilidad y validez, se prosiguió a realizar la evaluación del modelo mediante las cargas que se obtuvieron de los indicadores y las cargas mayores a 0.700 indican que el constructo explica el $50 \%$ de la varianza. Es por ello que en el modelo se optó por eliminar el ítem RT1 que corresponde al indicador de Toma de Riesgos, también se eliminó el ítem PR1 que corresponde al indicador de Proactividad, se eliminó CA3 de Competitividad Agresiva y finalmente se quitaron del modelo los ítems AT1, AT3, AT5 y AT6 del indicador de Autonomía, que fueron los items que no fueron significativos para dicho modelo (Tabla 1). Con ello, se pudo simplificar la multi-escala y mantener su estructura con las cinco dimensiones respectivas de la $\mathrm{OE}$ y sus respectivos ítems significativos.

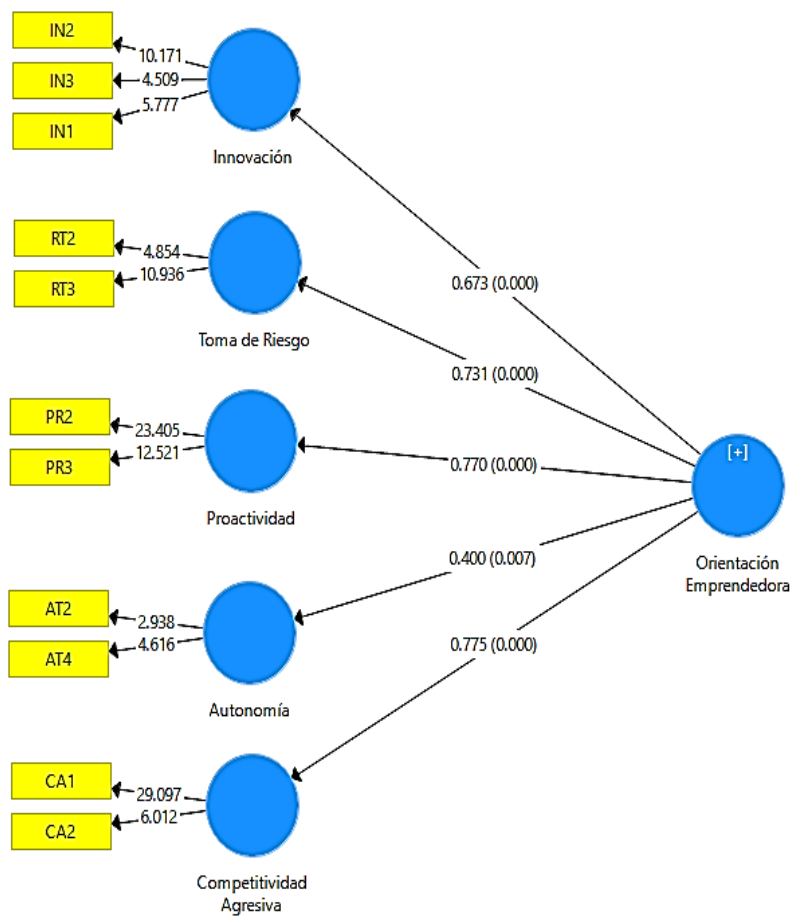

Figura 5 Modelo SEM PLS Ajustado

A partir de la magnitud de los coeficientes del modelo, se concluye que de las cinco dimensiones de la OE la más representativa para las mujeres gerentes, en el STC es la innovación, ya que es de vital importancia la creación de nuevos modelos de ropa, así como nuevos materiales y con una calidad superior, que les permita estar a la vanguardia de la moda y permanecer en el mercado, buscando nuevas formas de hacer el trabajo en el STC que genere una ventaja competitiva con respecto de la competencia, sobre todo extranjera, que maneja marcas internacionales de reconocido prestigio, esto es un verdadero reto para la región Sur de Guanajuato.
La toma de riegos también resultó ser crítica indican que las mujeres buscan que sus negocios crezcan y para ello, en ocasiones es necesario hacer nuevas inversiones en la compra de materia prima o maquinaria; que son lo medular de la inversión. En relación con las otras dimensiones, la productividad es relevante porque siempre es necesario buscar nuevas maneras de hacer las actividades que las mujeres desempeñan o hasta generar nuevas ideas en beneficio del negocio que lideran. La autonomía facilita a las emprendedoras, buscan ganarse la confianza de los jefes para tomar decisiones, sin tener que consultarlas directamente, y quizás esta dimensión sea la que más se tiene que trabajar, debido a la desconfianza que todavía existe en la gestión de una mujer gerente y a que en la mayoría de los casos no son todavía propietarias de los negocios, aspecto que las limita para una fluida toma de decisiones acertadas para mejorar la penetración de la empresa con nuevos modelos y diseños que sean competitivos frente a la ruinosa competencia proveniente del extranjero.

Y finalmente, la competitividad agresiva también se demuestra entre las encuestadas quienes han de deben implementar nuevas formas de llegar a los clientes, ofreciéndoles un catálogo amplio de diseños novedosos acorde a la moda, a los niveles de ingreso local y a las preferencias de estos clientes, logrando con ello, mantenerse en el mercado, tomando en cuenta la competencia internacional que ha sabido posicionarse en el mercado mediante el reconocimiento de las marcas reconocidas. Esto representa una debilidad muy fuerte para el clúster textil y de la confección en Moroleón, Uriangato y Yuriria, ya que carece de estas marcas que lo posicionen en el mercado sin riesgo de desaparecer.

Estas 103 mujeres con fuerte orientación emprendedora han demostrado que la mujer gerente del STC en la región de estudio, es tan capaz ya sea por necesidad u oportunidad de crear emprendimientos son capaces de atender las necesidades de los clientes, de crear fuentes de empleo y de contribuir a mejorar la condición socioeconómica de la empresa que dirigen y hacer un aporte importante a la producción local, al desarrollar la innovación, la proactividad y la toma de riesgos de una manera contundente, al crear valor para la cadena productiva en la que participan activamente y en la mejora del rendimiento de la empresa. 
Finalmente, se puede confirmar que el modelo planteado en el presente estudio cuenta con la fiabilidad y validez necesaria. Por lo que, es un modelo totalmente aceptado. Al mismo tiempo, el modelo de ecuaciones estructurales ha sido una técnica exitosa, pues se han aceptado todas las hipótesis que se realizaron al inicio de dicha investigación y se puede decir, que el rol de la mujer en la gerencia y/o dirección, en el sur del estado de Guanajuato, se manifiesta positivamente en la $\mathrm{OE}$, ya que hay un impacto significativo en las cinco dimensiones.

\section{Limitaciones y alcances de la investigación}

En el estudio de campo, se detectaron dos limitaciones. La primera fue el identificar fácilmente a las mujeres gerentes y/o dueñas de negocios, en los municipios de Yuriria, Uriangato y Moroleón, pues justamente, el STC cuenta con una mayor participación de mujeres, pero la mayoría de ellas están ubicadas en la parte de la manufactura que es el proceso de la elaboración de las prendas y no tanto, en puestos directivos.

La segunda limitante fue que al detectar a las mujeres que eran gerentes y/o dueñas de un negocio textil, algunas de ellas optaban por no contribuir a contestar el cuestionario, pues a pesar de que se les aclaraba que no se solicitaría información personal o muy comprometedora del negocio, pensaron que podía ser peligroso porque la información recolectada podía quizá utilizarse para generar un nuevo negocio y emular sus ideas o inclusive compartir dicha información con la competencia y afectar a su empresa.

El alcance más importante de esta investigación, fue identificar el rol de la mujer empresaria en la región Sur de Guanajuato, con alto nivel de $\mathrm{OE}$, pero con bajos niveles educativos y alta capacitación en la innovación organizacional, que permite manejar con excelente liderazgo, el logro de los objetivos organizacionales, la implementación, el seguimiento y el control de estrategias que aseguren el alto posicionamiento de sus empresas en el STC, logrando ventajas competitivas en el mercado doméstico con respecto a la competencia local. Otra situación se tendrá que desarrollar, si sus negocios quieren enfrentar la competencia agresiva de las marcas de reconocido prestigio nacional e internacional, en materia, sobre todo de la confección.
Para futura línea de investigación, está el realizar un estudio con una mayor muestra representativa del clúster textil y de la confección (cercana a 350 participantes en el levantamiento de la encuesta) para observar con más profundidad el comportamiento de la mujer gerente o directiva con $\mathrm{OE}$ en la gestión de negocios. Así como, evaluar si con este desempeño, se reduce la inequidad en percepciones y se obtiene un mayor y mejor impacto en el desempeño de las firmas que gestionan, frente al desenvolvimiento de estas dos variables, pero ahora dirigiendo hombres gerentes y/o directivos en el STC.

\section{Referencias}

Adams, S., Quagrainie, F. A., \& Klobodu, E. K. M. (2017). Women entrepreneurial orientation, motivation, and organizational performance in Ghana. Small Enterprise Research, 24(2), 189205.

https://doi.org/10.1080/13215906.2017.133963 1

Afandi, E., \& Kermani, M. (2014). Bridging the Gender Gap in Entrepreneurship: Evidence from Europe. So(2). https://doi.org/10.2139/ssrn.2425843

Álvarez, C., \& Urbano, D. (2011a). Factores del entorno y actividad emprendedora en América.

Álvarez, F. (2019). Gerentes y Emprendedoras: El efecto de la orientación emprendedora en el rendimiento de la PyME Guanajuatense del sector cuero-calzado por medio de ecuaciones estructurales (SEM-PLS). Management Review, 4(2). https://doi.org/10.18583/umr.v4i2.135

Andrade-Valbuena, N. A., Merigo-Lindahl, J. M., \& Olavarrieta S., S. (2018). Bibliometric analysis of entrepreneurial orientation. World Journal of Entrepreneurship, Management and Sustainable Development. https://doi.org/10.1108/wjemsd-08-2017-0048

Arroyo, M. y Cárcamo, M. (2010). Economía y Sociedad, Capitulo La Evolución historia e importancia económica del sector textil y del vestido en México. https://doi.org/10.1136/neurintsurg-2015012206 
Arunachalam, S., Ramaswami, S. N., Herrmann, P., \& Walker, D. (2016). Innovation Pathway to Profitability: The Role of Marketing Capabilities. Academy of Management Proceedings, 2015(1), 14430-14430. https://doi.org/10.5465/ambpp.2015.14430abstr act

Bolton, D. L. (2012). Individual entrepreneurial orientation: Further investigation of a measurement instrument. Academy of Entrepreneurship Journal, 18(1), 91-98. https://doi.org/10.1108/00400911211210314

Bolton, D. L. y Lane, M. D. (2012). Individual entrepreneurial orientation: development of a measurement instrument. Education + Training, 54(2/3), 219-233.

Busenitz, L. W., III, G. P., Shepherd, D., Nelson, T., Chandler, G., \& Zacharakis, A. (2003). Entrepreneurship research in emergence: past trends and future directions. Journal of Management, 29(3), 285-308.

Cho, Y. H., \& Lee, J.H. (2018). Entrepreneurial orientation, entrepreneurial education and performance. Asia Pacific Journal of Innovation and Entrepreneurship, 12(2), 124-134. https://doi.org/10.1108/apjie-05-2018-0028

Compean, M., Belausteguigoitia, I. y Navarrete, M. (2015). Una investigación sobre mujeres emprendedoras y propietarias de organizaciones familiares y no familiares en México. Mujeres Empresarias En Iberoamérica. Casos: España, México y Colombia, 1-34. Retrieved from http://cedef.itam.mx/sites/default/files/cedefita mmx/noticias/aadjuntos/2017/09/mujeres_empr esarias_y_propietarias_.pdf

Cultura, E. D. A., Breno, F., Ribeiro, G., Helena, T., \& Sanches, J. (2000). MULHERES EMPREENDEDORAS: O OLHAR A PARTIR DO ENTORNO ENVOLVENTE DA CULTURA Autoria Francisco Breno Gomes Ribeiro. 29 Enangrad Gestac Aprendizagem.

Fadda, N. (2018). The effects of entrepreneurial orientation dimensions on performance in the tourism sector. New England Journal of Entrepreneurship, 21(1), NEJE-03-2018-0004. https://doi.org/10.1108/NEJE-03-2018-0004
Fan, Y., Le, Z., Sheng, H. L., \& Zhang, K. Bin. (2012). Research progress of quorum sensing in Pseudomonas aeruginosa. Chinese Journal of Antibiotics, 37(1), 16-20. https://doi.org/10.1108/14626001111179749

Fellnhofer, K., Puumalainen, K., \& Sjögrén, H. (2016). Entrepreneurial orientation and performance - are sexes equal? International Journal of Entrepreneurial Behaviour and Research, 22(3), 346-374. https://doi.org/10.1108/IJEBR-12-2015-0286

Flores Novelo, A., Ojeda-Villagómez, F., Lee Kim, H. S., \& Ramírez Cedillo, E. (2017). Impacto de la Orientación Emprendedora en el Desempeño Empresarial: El caso de las empresas de Software en Yucatán, México. Faedpyme International Review, 5(9). https://doi.org/10.15558/fir.v5i9.117

Francoise, X. C. T., Julián E. P. O., \& Mejía Restropo. (2012). La mujer y el liderazgo empresarial * Women and Business Leadership Resumen. Diversitas: Perspectivas En Psicología, 8(1), 183-194. https://doi.org/ 10.15332/s1794-9998.2012.0001.12

Dess, G.G., \& Lumpkin, G.T. (2005), “The role of entrepreneurial orientation in stimulating effective corporate entrepreneurship", Academy of Management Executive, Vol. 19 No. 1, pp. 147-156

Fernández-Mesa, A., Alegre-Vidal, J., y ChivaGómez, R. (2012). Orientación Emprendedora, capacidad de aprendizaje organizativo y desempeño innovador. Journal of Technology Management \& Innovation, 7(2), 157-170. http://dx.doi.org/10.4067/S0718-

27242012000200013

Fuentes, M., Bojica, AM y Ruiz-Arroyo, M. Orientación emprendedora y adquisición de conocimiento: efectos sobre el desempeño en el contexto específico de empresas propiedad de mujeres. Int. Entrep. Manag J 11, 695-717 (2015). https://doi.org/10.1007/s11365-0140336-1

Galán, J., \& Sánchez-Bueno, M. (2009). The continuing validity of the strategy-structure nexus: new findings, 1993-2003. Strategic Management Journal, 30 (1), 1234-1243. 
García Vences, D.E., Plata García, A. A. (2017). Características de las mujeres emprendedoras. $V$ Congreso Virtual Internacional Sobre Transformación e Innovación En Las Organizaciones, (722), 211-220.

Greene, W. 2000. Econometric Analysis. Fourth Edition. Prentice Hall. 756 p.

Hernández, S., Fernández, C.C., \& Baptista, L.P. (2010) Metodologia de la investigacion quinta edición. México DF. McGraw Hill Educación.

Hormiga, E., de Saá-Pérez, P., Díaz-Díaz, N. L., Ballesteros-Rodríguez, J. L., \& Aguiar-Diaz, I. (2017). The influence of entrepreneurial orientation on the performance of academic research groups: the mediating role of knowledge sharing. Journal of Technology Transfer, 42(1), 10-32. https://doi.org/10.1007/s10961-015-9463-2

Júnior, E.I. and Gimenez, F.A.P. (2012), “An investigation of the reliability and validity of an entrepreneurial orientation index in Brazil", Academy ofEntrepreneurship Journal, Vol. 18 No. 2, pp. 41-56.

Kelly, L., \& Zaman, M. (2014). Entrepreneurial Orientation and Small Business Performance: The Role of Emergent Strategy. Ssrn, (September), https://doi.org/10.2139/ssrn.2486404

Kickul, J., Liao, J., Gundry, L. and Iakovleva, T. (2010b), "Firm resources, opportunity recognition, entrepreneurial orientation and performance: the case of Russian women-led family businesses", International Journal of Entrepreneurship and Innovation Management, Vol. 12 No. 1, pp. 52-69.

Kundu, S.C. and Rani, S. (2004), "Entrepreneurial orientation of aspiring managers: a study", International Journal ofManagement and Enterprise Development, Vol. 1 No. 3, pp. 233-250.

Kundu, S. C., \& Rani, S. (2016). Female aspirant human resources' entrepreneurial orientation: A study in Indian context. Management Research Review, 39(2), 235-263. https://doi.org/10.1108/MRR-11-2015-0267
Li, Y., Zhao, Y., Tan, J. and Liu, Y. (2008), "Moderating effects of entrepreneurial orientation on market orientation-performance linkage: evidence from Chinese small firms", Journal of small business management, 46 (1), pp. 113-133.

Lumpkin, G. T., \& Dess, G. G. (1996). Clarifying the entrepreneurial orientation constructand linking it to performance. Academy of Management Review, 21(1), 135172.http://doi.org/10.2307/258632

Maddala, G. 2001. Introduction to Econometrics. Third Edition. Wiley. 664 p.

Martínez, M., \& Fierro, E. (2017). Aplicación de la tecnica PLS-SEM en la gestión del conocimiento: un enfoque técnico práctico. Revista Iberoamericana para la investigación y desarrollo educativo, 8(16), 130-164. https://doi.org/10.23913/ride.v8i16.336

Ripollés, M. * Blesa, A. (2006). M . R IPOLLÉS * A . B LESA ** Redes personales del empresario y orientación emprendedora en las nuevas empresas $* * *, 73-93$.

Pérez, C. 2005. Métodos estadísticos avanzados con SPSS. Editorial Thomson. 792 p.

Ratten, V., \& Tajeddini, K. (2018). Women's entrepreneurship and internationalization: patterns and trends. International Journal of Sociology and Social Policy, 38(9-10), 780793. https://doi.org/10.1108/IJSSP-01-20180001

Raymond, L., Bergeron, F., Croteau, A. M., \& St-Pierre, J. (2015). Entrepreneurial orientation and E-business capabilities of manufacturing SMEs: An absorptive capacity lens. Proceedings of the Annual Hawaii International Conference on System Sciences, 2015-March, 3740-3749. https://doi.org/10.1109/HICSS.2015.450

Razo, A. (2017) Tesis de grado: Exportación como estrategia para impulsar la comercialización de la industria textil de los municipios de Moroleón y Uriangato. Universidad de Guanajuato. 
Renko, M., Carsrud, A., y Brännback , M. (2009). The effect of a market orientation, entrepreneurial orientation, and technological capability on innovativeness: a study of young biotechnology ventures in the United States and in Scandinavia, Journal of Small Business Management, 47(3), 331-369.

Richard, O.C., Barnett, T., Dwyer, S. and Chadwick, K. (2004), "Cultural diversity in management, firm performance, and the moderating role of entrepreneurial orientation dimensions", Academy of Management Journal, Vol. 47, pp. 255-66.

States, U., \& States, U. (2004). The Entrepreneurial Woman's Ca reer Model: Current Re search and a Ty po logi cal Frame work. Equal Opportunities International, (1990), 78-98.

Tsyganova, T. and Shirokova, G.V. (2010), "Gender differences in entrepreneurship: evidence from GEM data", Organizations and Markets in Emerging Economies, Vol. 1 No. 1, pp. 120-141.

Vargas, D. (2019). Aspectos metodológicos para la investigación social: modelos de ecuaciones estructurales. Universidad Nacional Autónoma de México.

Velazquez, M. (2014). Las mujeres en las pequeñas y medianas empresas ( pymes ) exportadoras . México : ¿ Una economía liderada por mujeres?

Zhang, H. Y., \& Yang, N. D. (2010). Clarifying the conceptualization and measurement of entrepreneurial orientation. 2010 International Conference on Management and Service Science, MASS 2010, (1996), 1-4. https://doi.org/10.1109/ICMSS.2010.5576440

Zimmerman, M. A., \& Brouthers, K. D. (2012). Gender heterogeneity, entrepreneurial orientation and international diversification. International Journal of Gender and Entrepreneurship, 4(1), 20-43. https://doi.org/10.1108/17566261211202963 